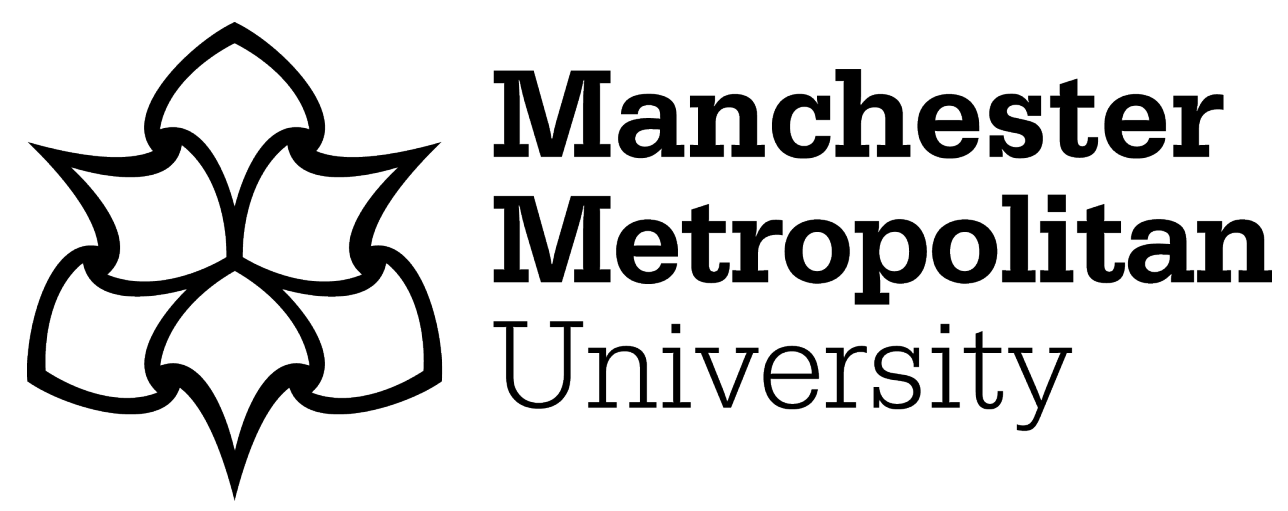

Trafi-Prats, L (2017) Learning with children, trees and art: Towards a compositionist visual art-based research. Studies in Art Education, 58 (4). pp. 325-334. ISSN 0039-3541

Downloaded from: https://e-space.mmu.ac.uk/620310/

Version: Accepted Version

Publisher: Taylor \& Francis

DOI: https://doi.org/10.1080/00393541.2017.1368292

Please cite the published version 


\section{Learning With Children, Trees, and Art: For a Compositionist Visual Art-Based Research}

\section{A U R A T R A FÍ - PRATS}

Manchester Metropolitan University

In this article, I discuss the concept of compositionism as an ontoepistemology of being and knowing that questions human exceptionalism. Compositionism suggests that humans exist in interdependence with complex bio-social systems that need to be assembled together with an ethics of response-ability toward threatened places and beings. I propose compositionism as a concept to inform the field of art education. I do this by devising correspondences between compositionist theory, childhood studies, and visual art-based research. I direct the implications of this discussion into selected passages of data from a study developed in collaboration with two classes of 5th-graders attending public school in a large city from the American Midwest. In this study, children used visual art-based methods, including drawing, video, print, and narrative to develop attentiveness and intimacy with a group of trees and tall grasses on the school block. 
- he concept of common world composition is central to a posthumanist turn in the studies of childhood. While psychology and sociology have traditionally understood children as beings that learn with other human beings about being human (Snaza, Sonu, Truman, \& Zaliwska, 2016), posthumanism envisions children as working intra-actively with multiple others (Murris, 2016). Intra-action is a concept that childhood studies takes from physicist and philosopher Karen Barad (2007) to describe dynamic relations in which entities do not pre-exist the relation but are formed by it. Following Barad, LenzTaguchi (2009) suggested that research about/with childhood is developed in an onto-epistemology where theories of being (ontology) are interdependent with theories of knowing (epistemology).

In this onto-epistemology, human intentionality is not interpreted as the origin of all activity, but agency is seen as "diffusively enacted in complex networks of relations" (Alaimo \& Heckman, 2008, p. 13). Consequently, doing research about/with children requires an immersed, processual approach in which all participants are affected and modulated by "events of an intertwined material-discursive and embodied reality" (Lenz-Taguchi, 2009, p. 90), and where "the story of the research is constantly becoming something different" (Sellers, 2013, p. xix).

Situated in the philosophical context of posthumanism, the concept of common world composition seeks to respond to the many lifethreatening challenges posed by the Anthropocene through promoting pedagogies centered on the interdependence among children, things, environments, and other biosocial forces (e.g., Pacini-Ketchabaw, Taylor, \& Blaise, 2016; Taylor, 2013; Taylor \& PaciniKetchabaw, 2015). The Anthropocene is one of the different terms used to define humanly created geological changes, mostly due to the exacerbated use of fossil fuels after World War II, that have irreversibly transformed the planet biosphere (Crutzen, 2006; Haraway, 2016).

In the context of the Anthropocene, compositionist researchers working in education consider that building intergenerational and interspecies bonds is simply part of an "inexorable" (Taylor \& Pacini-Ketchabaw, 2015, p. 509) fate, if there is to be any fate at all. These researchers claim that to ensure the survival of our species we need pedagogical practices centered on forming sustainable caring relations with multiple more-than-human others.

The concept of common world composition comes from Bruno Latour's (2010) philosophy. Put simply, compositionism means that humans live as parts of systems. These systems are not pre-existent but must be composed with discontinuous parts. As Latour (2010) explained, one of the central traits in composing common worlds is that the heterogeneity of the many is retained in their assemblage. For Latour (2010), the idea of composing has roots in the accumulated knowledge that the arts have in putting together innovative compositions with all sorts of semiotic-material and spatial-temporal components. Latour (2010) affirmed that composing is also about compromising and getting along with radically 
different others. Composing links to composting too, in the sense that all composition contains its decomposition.

For Latour (2004), there is a sense of ordinariness in composing. Common world compositions are located in everyday places where humans are not exceptional and separated from other entities in the world. The concept of common world composition disputes the idea of a nature-culture binary, by arguing that nature is not an existing thing but an "organizing division between appearances and reality, subjectivity and objectivity" (Latour, 2010, p. 476). Social research has engaged with the concept of nature as a way of exercising and distributing power through the distinction of what can be and cannot be discussed, and of what is universal and immutable and, consequently, remains outside the realm of critique.

Despite Latour's (2010) affirmation that nature does not exist, the nature-culture binary is still in vogue today through the movement of returning childhood to nature (e.g., Louv, 2005). In this movement, nature is uncritically positivized as an unmediated space that is good for the child. However, as Taylor (2013) suggested, this newly proclaimed return to nature tends to obscure accumulated decades of ecological damage and issues of environmental injustice. For some children who live in threatened and threatening places, the prospect of spending time outside is not seen as a positive one. For instance, the city where my study took place is known for its abundance of public parks and fresh water resources. However, large pockets of the city's population, including children in the classroom where the study took place, live far away from fresh food outlets and parks as a result of segregationist spatial practices. My research journal contains blurbs of a few situations that show that for a number of children, the outside was populated by unwelcoming materialities. Children spoke with concern about the extreme cold and their lack of appropriate winter gear, of the blackened mountains of dirty accumulated snow, of the possibility of stepping on unperceived street cracks filled with water and mushy leaves that get their feet wet, and of the encounter with spaces showing signs of vandalism and trash. As Taylor (2013) contended,

common worlds are not separated, pure and natural utopic spaces. They are mixed up worlds in which all manner of things co-exist.... In other words, children common worlds are impure and emerging worlds, produced through ongoing heterogeneous relations that take place within and between a whole host of actors. (p. 80)

Through my compositionist visual artbased study, I learned that not having a desire for the outside should not have been seen as a limitation but needed to be understood as a specific way of composing with a number of heterogenous entities and discourses that orientated children toward specific inhabitations of public space-inhabitations that possibly resulted from heterogeneous compositions: geopolitics of space in the city with children's life experiences with Cartesian organizations of how and where learning takes place in school, with, with, with, with. The many possibilities of worlding with the bio-social ecologies of the city required an understanding that children could enter into relations with the street, the trees, and the bushes at different moments and from different points, including not being outside.

In this article, I hold onto the idea of not desiring to be outside as an important point defining relations between urban bodies and urban materialities. I use it to enter selected fragments of data, connected with a girl called Quvenzhané, ${ }^{1}$ who decided not to participate in any of the six outings that set the beginning of the study and my collaboration with the children. I think with the theories of compositionism and visual art research to map this fragment with other fragments of data and 
research events connected to Quvenzhané that happened through the course of the project. In doing this, I seek to explore: how the materiality of visual art-based research can activate experimental, non-normative approaches to knowing and experiences of getting along with others in an ethics of immanence and potentiality.

The study began with a series of six outings on the school block. Groups of three to four students chose a tree to research with their senses. For this, I proposed using methods such as drawing, rubbing, printing, writing, videorecording, or collecting to propel attentive modes of being with the trees, foster interconnections with different senses (Pink, 2009), and activate collective ways of learning with other species (Pacini-Ketchabaw et al., 2016). In these six outings, Quvenzhané chose to do other school activities and did not come outside to be with the trees. Two weeks into the project, she specifically refused my personal invitation to engage in sensorial research with the trees and grasses. I said, "You may enjoy it, your peers are doing interesting work, give it a try." Quvenzhané responded that the grasses were “muddy and dirty... I don't want to put my feet in there." ${ }^{2}$ Quvenzhané usually dressed up for school with carefully matched tops and bottoms, and formal shoes. That specific day, she wore a pair of silvery sandals with medium heels.

This research event reveals that non-human and material forces are at play in making Quvenzhané decide not to be with the trees. These material forces include wetness, dirt, mushy textures, shiny silvery shoes affectively creating directions, speeds, connections, and disconnections (Delanda, 2006), and eventually retracting Quvenzhané from building a relation with others, including peers, trees, bushes, and the street.

\section{Compositionism and the Prosthesis of Visual Arts-Based Research}

Latour (2010) affirmed that compositionism is "a search for the common" (p. 488). By common he does not imply the same, but a space- time of commonality and conviviality where "utterly heterogeneous parts exist... never [to] make a whole, but at best a fragile, revisable, and diverse composite material" (p. 474). He continues to assert that common world compositions "have to be slowly composed instead of being taken for granted and imposed on all" (p. 488). I suggest that Latour's defense of heterogeneous compositions resonates with Garoian's (2013) concept of prosthesis.

For Garoian (2013), prosthesis constitutes an approach to knowing in practices of artmaking in which heterogeneous forms of knowledge are linked together. The experience of artmaking brings the subject to encounter the limits of knowing in rationalistic, striated systems. Such crisis of understanding opens up to new possibilities of thinking and living that "disarticulate and counter-actualize universalizing assumptions and practices" (Garoian, 2014, p. 389). It is in this sense that, for Garoian (2013), practices of visual art-based research allow for a slippage of meaning because the experience of artmaking creates dislocations and disconnections so anomalous forms of knowledge coexist in productive indeterminacy with institutionalized discourses and habituated practices.

In this respect, Garoian's $(2013,2014)$ ideas on prosthesis present potential correspondences with Latour's (2010) affirmation that there is always a supplemental gap between what rationalism calls causes and consequences. Latour (2010) described this gap in terms of "discontinuity, invention, supplementarity, creativity" (p. 483). Latour (2010) affirmed that "consequences overwhelm their causes, and this overflow has to be respected everywhere, in every domain, in every discipline, for every type of entity" (p. 484).

By putting Latour $(2004,2010)$ and Garoian (2013) in productive dialog, I think of my research project involving children-trees-streetart encounters as heterogeneous entities slowly composing together not because they had to but because it was possible. That is, I understand 
"possible" as supplemental, indeterminate, prosthetic, compositional, emergent, and intra-active. I intend to elaborate on this idea through another fragment of data that is still connected to the proposition of researching the trees with the senses and through methods of artmaking.

As the outings progressed, the focus on sensorial experience shifted to a focus on knowledge. An interest in classification and scientific control started to proliferate among some children. The detailed attention toward the trees that drawing, rubbing, print collecting, and video-taping brought worked intraactively with what the 5th-grade curriculum valued as scientific knowledge. The children had been schooled for so long in structures of intelligibility based on the cogito that they could not bear to regard themselves as enmeshed in fluxes of activity. They needed to return to stabilized identities (Colebrook, 2001). In trying to know the trees with the senses, children felt the disequilibrium of something unsettling that resisted being assimilated into their pre-existing frameworks of understanding (Garoian, 2013).

In light of these circumstances, I thought that the project needed a new research proposition to reorient the process ontologically "from individual human to collective morethan-human subjectivities and agencies" (Pacini-Ketchabaw et al., 2016, p. 150). Considering this, I brought to the class The Night Life of Trees (Bai \& Shyam, 2006), a large book created by Gond artists that displays original block prints and includes stories about trees and what happens to them at night. Gonds are an ethnic group from the forests of Chennai, India. Tree species, fauna, foods, matter, and crafts specific to the biodiversity of the Gond forest are featured in the stories not as brute facts but as elements that add verisimilitude to stories that clearly appeal to the powers of the imagination. In introducing this book into the research process, I sought to create a situation similar to what Garoian (2013) described as prosthetic mimesis, in which emulation of a cultural-material object like The Night Life of Trees can lead to inventiveness. This is done by setting the referent in relation to a series of active conditions. In our case, these conditions included reading and looking at the book, and sketching and writing their images and stories about what possibly happened at night to the trees they had spent time with during the outings. Additionally, I suggested combining their images with their narratives and elements of science with elements of fiction.

In the unfolding of this research proposition, children elaborated drawings and prints that prosthetically linked conventional understandings of scientific facts of tree species with fantasy plots derived from the young-adult books they were checking out from the library and games they were playing at home. Some prints and narratives included elements of other current assignments, including a report on an endangered animal. Many narratives presented conflicted, hybrid, power-ridden worlds of multispecies struggle. In this respect, the narratives and prints constituted an example of heterogeneous common world compositions assembled from many semiotic and material fragments.

The section that follows theoretically elaborates on the analysis of the narratives and prints above. To do this, I deepen my focus on Quvenzhané's being and becoming through the project. I look in detail at how she encountered The Night Life of Trees (Bai \& Shyam, 2006), and how the book acted on her. My analysis sets in relation Haraway's (2016) SF compositionist philosophy with O'Donoghue's (2015) study on how art lends a potentiality for thinking and becoming.

\section{Arts of Living and Thinking Potentiality}

Haraway (2016) described SF as a sign that simultaneously stands for String Figures, Science Fiction, Speculative Fabulation, Speculative Feminism, and Science Fact. SF constructs alliances between art, science, and activism to devise a cosmopolitics of 
alternative patterns of composition so that "ontologically heterogenous partners become who and what they are in relational materialsemiotic worldings" (p. 13).

Additionallly, SF refers to everyday practices of storytelling that are in-the-making, in which facts and fiction are connected, and real beings mix with creatures of the imagination. SF alludes to the power of art to make us think and be ethically responsive to the patterns of connection that make worlds. SF prompts us to interrogate how life continues when one of the elements of the pattern disappears. How do the survivors existentially, artistically, scientifically, and politically respond to such loss with their own lives? For Haraway, art builds powerful encounters with images and narratives of life, loss, and partial recuperation. She sees the arts as being essential in the cultivation of forms of public response-ability that invite viewers, readers, and players to become enfolded with others (artists, scientists, activists) "in diverse passionate, corporeal, meaningful ways" (p. 72).

I want to situate Haraway's (2016) SF philosophy in parallel with O'Donoghue's (2015) discussion on the potentiality for thinking that is enacted through contemporary art projects centered on delivering experiences. O'Donoghue (2015) argued that the experience in which the viewer is enfolded in this specific type of art project constitutes a way of living in the world that could not have been thought possible until lived. In tune with Haraway (2016), O'Donoghue (2015) contended that it is worthwhile to engage in experiencing, thinking, and writing creative work that radically engages in the arts of living in a complex, damaged world. This engagement carries the possibility to reorient us ontologically by augmenting our awareness on the multiplicity of approaches to compose, relate, and build alliances with others, and on the existential possibilities these approaches might engender.

In introducing The Night Life of Trees (Bai \& Shyam, 2006) to the children, I thought that the book with its beautiful images, intricate graphics, mysterious stories, bright colors, aromas of organic inks, and rich paper texture could open an alternative time-space to reexperience the trees with the senses. I thought that the experience of the book could "cultivate an attitude of openness, curiosity, inquiry, delayed judgement" (O'Donoghue, 2015, p. 110), and disrupt the representational impulse of classifying, analyzing, and reducing the trees to language. For a few sessions, I sat with the children and did group readings of the book. We looked at and talked about the pictures. During one of these readings, a conversation began about what pictures and stories we liked the best. Quvenzhané was sitting in on this conversation, and after few of her peers talked about their favorite trees, she pointed at the story and print Snakes and Earth, and said:

Quvenzhané: I like the snakes, how they are put together, I guess. I also like that the snakes are black.

Laura: Yes, they are all black with different color patterns! What is it that you like about the fact that they are black?

Quvenzhané: I do not know, but I like it.

This was the first time that Quvenzhané contributed to the project. She did this without being asked, which made me think that what she had to say was important. Since I did not expect to hear what she said, and she could not fully explain what she meant, silence followed. I felt that in the liking-the-snakes-beingblack there was something difficult that was not able to be expressed with words; perhaps something seductive, visceral, affective, and indeterminate made it impossible to be articulated with the linear structure of language (MacLure, 2016). Not reducing liking-thesnakes-being-black to a symbolic meaning allows for an understanding of Quvenzhané's experience as one of potentiality. It demands thinking about the book as agential, considering how the large, thick, and textured black 
page imprinted with the brightly colored image of a snake-shaped tree was sensed and embodied by Quvenzhané. It requires noticing that in the utterance liking-the-snakes-beingblack there is something trying to come-intobeing, which requires time-space for further exploration. Posthumanism speaks of an ethics of immanence and potentiality that Haraway (2016) described with the expression "staying with the trouble" (p. 4). Trouble stands here for what is odd, messy, different, and emergent, but that in any case calls for response. Educators and researchers respond by allowing time-space in which children unravel and grapple with what is emerging from the problems that they come up with (Lenz-Taguchi, 2009), problems like liking-the-snakes-being-black.

In the weeks that followed this conversation, I saw Quvenzhané returning to the book, reading the stories and looking at the images. She asked me for materials to sketch her tree at night. Using the book as a reference, she drew a tree that mimicked the aforementioned print Snakes and Earth. After this, she actively engaged in learning how to transfer her drawing into a foam plate, engraving the plate, and printing different versions of her tree.

\section{Working in the Edge of the Unthought}

In this final section, I prolong the discussion of what it means to work with an ethics of immanence and potentiality when confronted with the strange, discontinuous, hardly verbal fragments of data that Quvenzhané enacted. Borrowing Haraway's (2016) words, one thing that can be said from a compositionist point of view is that research and learning are always "made of partial connections and not universals or particulars" (p. 13). As discussed earlier with Latour's (2010) and Garoian's (2013) theories, the connections that I am mapping of Quvenzhané's becomings are neither foreseeable, nor given. I have composed them in trying to make sense of the data. Doing research in an ethics of immanence and potentiality attends to acts of thinking that move in many directions, come in different modalities, and perform surprises (Sellers, 2013), as Quvenzhané's data show.

It is in this light that I present these final passages of data. They correspond to the third research proposition, which consisted of bringing back the groups that had investigated together the same tree, to edit a mini videonarrative compiled from the footage they had recorded during the outings. I invited the children to review their footage, along with their collections, drawings, fieldnotes, prints, and stories, and to choose one piece to present it in front of a camera. This idea followed Deleuze's (1989) argument that the cinematic image is not one that represents the world, but rather is one to think with about what does not exist in the world yet, but that can articulate itself to exist cinematically. The aim was not for the children to simply display their footage, art, and findings about the trees, but to craft and edit images that offered an experience of the trees to others. I thought of these mini video-narratives in terms of what Deleuze (1989) described as collective utterance, in which people by telling and performing fictional stories become other. This is what Deleuze (1989) called the "invention of a people" (p. 212), or people to come, a concept that describes a radical movement of immanence and becoming.

Initially, Quvenzhané told me that she did not want to participate in the making of the video. I asked her about the possibility of doing something with the drawing that she had created for the night life of her tree print. She explained that she had a drawing but not a story. I suggested that perhaps the video was a good opportunity to write the story, and she agreed. This is the story that Quvenzhané wrote and performed in front of the camera:

One day a dude came from out of town. He was a mean person. He hated trees because a tree had fallen in his house and hurt it badly. So, he saw a beautiful red maple tree, as red as the bricks of his house and cut it down with a big and noisy 
chain saw [few seconds of loud engine noise]. It was so noisy that all the snakes in town came by. The snakes were sad that the tree had lost everything, including the leaves. It was hot and the snakes were hoping for a nice and good shade. So the snakes put the leaves back and their bodies became branches and roots. And now every time the wind blows everybody can hear some rattling coming out from the tree [few seconds of rattle noise].

Quvenzhané's story depicts an SF common world of ecological trouble and exploitation. We do not know what happens to the human after his act of violence. The snakes enter the story not as avengers but to compose with the tree and render each other capable, not as a response to the actions of the human. There is suffering, rage, and violence, but all this results in a story about alternative living arrangements, in which the snakes co-compose symbiotically with the tree.

Quvenzhané created a second video-image in collaboration with her friend Selena. Like Quvenzhané, Selena wanted to show and tell the story of her tree. To do so she positioned herself against the light coming from a window. The computer camera responded to the main source of light and as a consequence darkened Selena's face. Quvenzhané offered to block the light by standing in front of the window. As Selena recounted her story, Quvenzhané began to gesture, dance, and momentarily embody an iconic pose of girl-power with a risen fist. Selena noticed all this in the computer screen as she was reciting. They both got really excited, and decided to record again with Selena narrating the story while Quvenzhane stood in the background in the pose.

These two video images can be conceptualized in relation to what Marks (2000) described as radioactive recollection images. These are images that are strange and unclassifiable. They do not correspond to a memory, or story of a real event. Marks (2000) described them as powerful images that function as an index pointing toward something that needs to exist, but that the characters of this cinema have no words to express. They are images that simply presented to the senses. This is what happens in the first image, in which Quvenzhané appears in front of the camera reading the story of her tree with her BlackEnglish accent, being interrupted by the sounds of the chain saw and the rattle snakes, with her face collapsed and partly covered by the display of the drawing. Marks (2000) affirmed that radioactive recollection images are images that are not instrumental; they do not aim to represent anything, but function as "residual nonverbal knowledges [that] remain a body repository that can only be understood in its own terms" (p. 71).

These two images ${ }^{3}$ show that in an ethics of immanence and potentiality, the materiality of learning includes many registers and modalities, and that processes of artmaking allow for its emergence and recognition. These two images display learning as sensorial, embodied, durational, and visual. They display the rich, hybrid, and queer qualities of common worlds made of multidirectional, multispecies encounters between children-trees-art-video.

Doing visual art-based research in an ethics of immanence and potentiality brings with it the possibility of working with data, like the two images produced by Quvenzhané and Selena, in terms of wonder rather than representation. MacLure (2013) related wonder to the type of qualitative research developed in the 17th century with cabinets of curiosity, where the display of objects allowed for an interplay of order and disorder, and "attuned to the lively excess that always exceeds capture by structure and representation, leaving openings where something new, or something else, might issue" (p. 229). In this antirepresentational approach to research, we work on the edge of the unthought, but in doing this we regain a new life by collectively evoking theories that can think it, images that can imagine it, and stories that can compose it. 
Following this idea of collective evocation, the proposition that culminated the project was the design of an exhibition, which opened on graduation night. It created a space for the children and their families to share the project; to look at the prints; read the night life of the tree stories; and watch the video-essays in an SF composition of science facts and speculative fabulation. The beauty of the prints, the inventiveness of the stories, the visual descriptions of the video provoked wonder and curiosity in our visitors. The exhibition offered a place "to cultivate the capacity to respond" (Haraway, 2016, p. 78) to stories that seek to compose worlds in terms of complexity where spaces, times, bodies, things entangle in multispecies arrangements. These are stories that propel us to think about research and pedagogy as spaces for embracing learning and thinking in terms of uncertainty, for paying close attention to processes of being and becoming while stopping to privilege knowledge, representation, and closure as the defining aspects of the research event (Snaza et al., 2016).

\section{Conclusions}

I have discussed how the compositionist philosophies of Latour $(2004,2010)$ and Haraway (2016) work along with concepts and practices of visual art-based research advanced by Garoian (2013, 2014) and O'Donoghue (2015). I have reflected on how compositionist philosophies can inform and shape a post-humanist approach to art education research concerned with processes of teaching and learning art in common worlds and through multispecies encounters. Compositionist researchers and educators understand the spaces, bodies, things, texts, technologies, and other realities that form a school as a more-than-human ecology of practice. They show us the need to create pedagogical spaces where open-ended, iterative, exploratory processes that allow deviations, elaborations, and material play interact with facts and fiction (Haraway, 2016). In compositionist philosophies, adults and children can learn together, and with other species, forms of responding to what is different, odd, ongoing, emergent, or existential in the intra-actions between art, science, learning, living, and dying. The idea here is not to use research and pedagogy to reduce reality to one level of understanding that segregates others (Latour, 2010), where art, science, writing, being inside, and being outside are succinct and disconnected experiences. Working with an SF approach allows for thinking about science facts and speculative fabulation as parts of the same level of reality.

Taking as a point of departure a common worlds project of encounters between children, trees, and tall grasses on the school block, I have elaborated and exemplified how the encounter of compositionist philosophies with visual artsbased research is a fertile one. Visual arts-based research offers a framework for experimentation and fragmentary composition of multiples (Garoian, 2013). Visual arts-based research considers indeterminacy and disequilibrium as a space of potentiality where transformative pedagogical events can unfold (Garoian, 2014). Visual arts-based research contributes to the speculative and ontological efforts of compositionism by focusing on art experiences that have the power to affect how we see and inhabit the world with others (O'Donoghue, 2015). In summary, a compositionist visual art-based research works in an ethics of immanence and potentiality that allows for partial and provisional encounters with data, showing that the composition of common worlds is a slow, ongoing, discontinuous, fragile, and problematic process with which the researcher and participants engage in acts of response-ability.

\section{REFERE N C E S}

Alaimo, S., \& Heckman, S. (2008). Introduction: Emerging models of materiality in feminist theory. In S. Alaimo \& S. Heckman (Eds.), Materialist feminisms (pp. 1-19). Bloomington, IN: Indiana University Press.

Bai, D., \& Shyam, B. (2006). The night life of trees. Chennai, India: Tara Books. 
Barad, K. (2007). Meeting the universe halfway: Quantum physics and the entanglement of matter and meaning. Durham, NC: Duke University Press.

Colebrook, C. (2001). Gilles Deleuze: Essential guides for literary studies. London, England: Routledge.

Crutzen, P. (2006). The Anthropocene. In E. Ehlers \& T. Krafft (Eds.), Earth system science in the Anthropocene (pp. 3-11). Berlin, Germany: Springer.

Delanda, M. (2006). A new philosophy of society: Assemblage theory and social complexity. London, England: Continuum.

Deleuze, G. (1989). Cinéma II: The time-image. Minneapolis: University of Minnesota Press.

Garoian, C. (2013). The prosthetic pedagogy of art: Embodied research and practice. Albany: State University of New York Press.

Garoian, C. (2014). In the event that art and teaching encounter. Studies in Art Education, 56(1), 384-396.

Haraway, D. (2016). Staying with the trouble. Making kin in the chthulucene. Durham, NC: Duke University Press. Latour, B. (2004). Politics of nature: How to bring the sciences into democracy. Cambridge, MA: Harvard University.

Latour, B. (2010). An attempt at a "Compositionist Manifesto." New Literary History, 41, 471-490.

Lenz-Taguchi, H. (2009). Going beyond/theory/practice divide in early childhood education: Introducing an intraactive pedagogy. London, England: Routledge.

Louv, R. (2005). Last child in the woods. Saving our children from nature-deficit disorder. Chapell Hill, NC: Algonquin Books.

MacLure, M. (2013). The wonder of data. Cultural Studies <-> Critical Methodologies, 13(4), 228-232.

MacLure, M. (2016). The refrain of the a-grammatical child: Finding another language in/for qualitative research. Cultural Studies <-> Critical Methodologies, 16(2), 173-182.

Marks, L. (2000). The skin of the film: Intercultural cinema, embodiment, and the senses. Durham, NC: Duke University Press.

Murris, K. (2016). The posthuman child. London, England: Routledge.

O'Donoghue, D. (2015). The turn to experience in contemporary art: A potentiality for thinking art education differently. Studies in Art Education, 56(2), 103-113.

Pacini-Ketchabaw, V., Taylor, A., \& Blaise, M. (2016). Decentring the human in multispecies ethnographies: Bridging the divide. In C. A. Taylor \& C. Hughes (Eds.), Posthuman research practices in education (pp. 149-167). London, England: Palgrave.

Pink, S. (2009). Doing sensory ethnography. London, England: SAGE.

Sellers, M. (2013). Young children becoming curriculum: Deleuze Te Whariki and curricular understandings. London, England: Routledge.

Snaza, N., Sonu, D., Truman, S., \& Zaliwska, Z. (2016). Re-attuning to the materiality of education. In N. Snaza, D. Sonu, S. Truman, \& Z. Zaliwska (Eds.), Pedagogical matters: New materialisms and curriculum studies (pp. xvxxxiii). New York, NY: Peter Lang.

Taylor, A. (2013). Reconfiguring the natures of childhood. London, England: Routledge.

Taylor, A., \& Pacini-Ketchabaw, V. (2015). Learning with children, ants, and worms in the anthropocene: Towards a common world pedagogy of multispecies vulnerability. Pedagogy, Culture \& Society, 23(4), 507-529. doi:10.1080/14681366.2015.1039050

\section{E N D N O T E S}

${ }^{1}$ All the names used in the article that refer to research participants are pseudonyms.

2 These quotes correspond to transcriptions of the aforementioned conversation with Quvenzhané. I wrote them in my field journal a few minutes after the conversation took place.

${ }^{3}$ I have chosen not to publish visual samples of these two images for ethical reasons. They clearly expose the faces and gestures of these two young girls, and my ethics consent forms only allowed the publication of indirect images where facial recognition was not possible. 